56

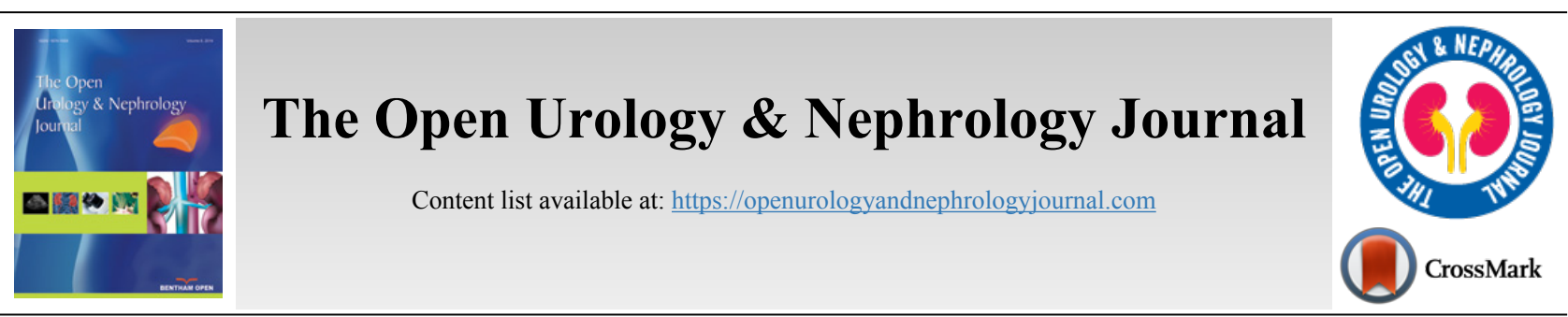

CASE REPORT

\title{
Primary Extranodal Diffuse Large B Cell Lymphoma Masquerading As Acute Pyogenic Myositis: A Case Report
}

\author{
Manisha Dassi $^{1, *}$, Garima Aggarwal ${ }^{1}$, Lakshmi K. Jha $^{1}$ and Neeru P. Aggarwal ${ }^{1}$ \\ ${ }^{1}$ Max Super Speciality Hospital, Vaishali, Ghaziabad, Uttar Pradesh, India
}

\begin{abstract}
Diffuse Large B Cell Lymphoma is the commonest subtype of Non-Hodgkin's Lymphoma. It may present with primary nodal or extranodal involvement. Up to $40 \%$ of patients present with primary extranodal involvement, the commonest involved sites being gastrointestinal tract, testes, central nervous system, thyroid, nose, sinuses, skin, breast, bone and respiratory tract. Skeletal Muscle is a rare site of primary lymphomatous involvement. We present a case of Diffuse Large B Cell lymphoma primarily involving the skeletal muscles and breast, initially managed as a case of acute pyogenic myositis with sepsis with Multiple Organ Dysfunction Syndrome. In addition, the patient had hypercalcemia cortical vein thrombosis, proteinuria and renal dysfunction, which were all speculated to be paraneoplastic in etiology.
\end{abstract}

Keywords: Diffuse large B cell lymphoma, Extranodal lymphoma, Skeletal muscle, Paraneoplastic, Etiology, Myositis.

\begin{tabular}{|l|l|l|l|}
\hline Article History & Received: February 13, 2019 & Revised: May 24, 2019 & Accepted: July 30, 2019 \\
\hline
\end{tabular}

\section{INTRODUCTION}

Non-Hodgkin's Lymphoma is the most prevalent lymphohematopoietic neoplasm in India [1,2] and the world over [3, 4]. Diffuse Large B cell lymphoma is the commonest subtype $[1,4]$. Extranodal tissue involvement is not uncommon among lymphomas. Non-Hodgkin's lymphoma may have primary extranodal involvement [5]. In up to $40 \%$ of the patients, Diffuse Large B Cell Lymphoma may primarily involve extranodal sites, including gastrointestinal tract, testes, central nervous system, thyroid, nose, sinuses, skin, breast, bone and respiratory tract [5]. However, skeletal muscle is one of the rarest sites of extranodal involvement [6]. In addition, patients might rarely present with simultaneous involvement of multiple extranodal sites [7]. Here, we present a case of Diffuse Large B Cell Lymphoma primarily involving skeletal muscles and breast along with hypercalcemia, hypercoagulable state, proteinuria and renal dysfunction.

\section{CASE REPORT}

A 55 years old male, a diabetic and hypertensive patient since 8 years, presented with a history of high grade fever, rigors and chills and a painful right thigh swelling since 10 days; oliguria, periorbital puffiness, drowsiness, slurring of speech and right leg weakness since 4 to 5 days. His medications included oral antidiabetic drugs and Losartan.

* Address correspondence to this author at the Max Super Speciality Hospital W-3, Near Radisson Blue Hotel, Sector 1, Vaishali, Ghaziabad, Uttar Pradesh, 201012, India; Tel: +918527066844; E-mail: manishadassi@gmail.com
The patient had initially presented at another hospital 8 weeks prior with a history of high grade intermittent fever, gradually progressive right thigh pain, diffuse swelling and tenderness from past 6 to 7 days. Investigations done at that time revealed Haemoglobin $8.0 \mathrm{gm} / \mathrm{dl}$, Total leucocyte count $24000 / \mathrm{uL}$, and platelets $90,000 / \mathrm{uL}$. Serum biochemistry was as follows: Creatinine $2.5 \mathrm{mg} / \mathrm{dl}$, Creatine Phosphokinase(CPK) $210 \mathrm{IU} / \mathrm{L}$, Procalcitonin $75 \mathrm{ng} / \mathrm{ml}$, Aspartate Transaminase(AST) and Alanine Transaminase(ALT) were 100 and 150 U./L, respectively. Urinalysis showed $3+$ proteinuria and no microhaematuria. Blood and urine cultures were sterile. Magnetic Resonance Imaging (MRI) of thigh Fig. (1) revealed intra and inter muscle plane edema in all compartments of right thigh and muscles of right side of pelvis with areas of the focal collection. Chest X-Ray and ultrasonographic examination of the abdomen were normal. He was diagnosed to have pyogenic myositis with sepsis and Multiple Organ Dysfunction Syndrome and was treated with intravenous antibiotics, surgical debridement and drainage of pus along with supportive treatment. The patient improved clinically with complete resolution of thigh pain, swelling and fever.

After 8 weeks, he presented at our hospital again with complaints of fever and recurrence of painful right thigh swelling since 10 days; decrease in urine output, periorbital puffiness, drowsiness, slurring of speech and weakness in the right leg from past of 4 to 5 days Clinical examination revealed pallor, anasarca, slurring of speech, poor sensorium, right leg monoparesis (power $3 / 5$ ) with right extensor plantar response, 


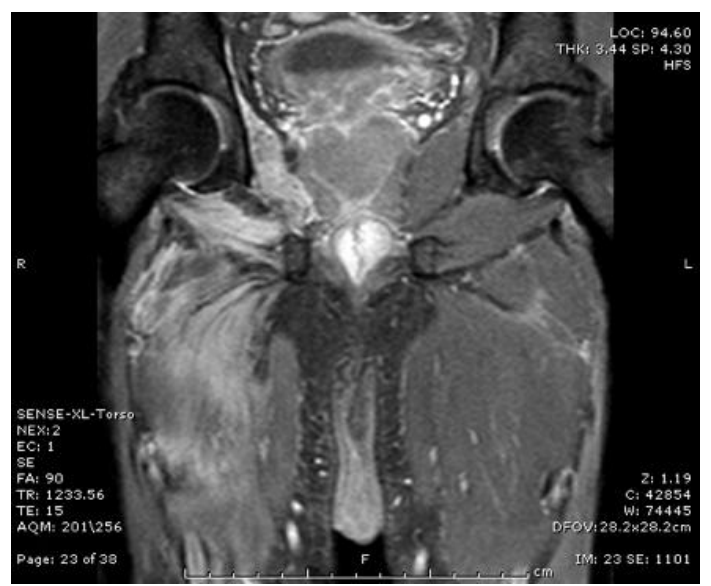

Fig. (1). MRI Thigh showing Intra and Inter muscle plane edema in all compartments of right thigh.

right thigh diffuse tender swelling with overlying skin induration and erythema and a freely movable, mildly tender, non-inflamed left breast lump.

Investigations revealed haemoglobin $7.8 \mathrm{gm} / \mathrm{dl}$, TLC $24000 / \mathrm{uL}$, platelets $75000 / \mathrm{uL}, \mathrm{S}$. Creatinine $5.6 \mathrm{mg} / \mathrm{dl}$, S. Calcium $16.3 \mathrm{mg} / \mathrm{dl}$, immunoreactive parathyroid hormone (iPTH) $2.8 \mathrm{pg} / \mathrm{ml}$, S. Albumin $2.5 \mathrm{gm} / \mathrm{dl}$, and CPK $511 \mathrm{IU} / \mathrm{L}$. Urinalysis showed 3+ proteinuria and 10-12 leucocytes/ high power field. Urine spot Protein Creatinine Ratio (PCR) was 2.6. MRI Brain with venography was suggestive of cortical vein thrombosis. Serum and Urine Protein Electrophoresis did not reveal any M Spike. Serum free Kappa/Lambda Chain Ratio was 1.6. His complement levels were normal. ANA, Anti dsDNA and ANCA were negative. ENA Panel (comprising Anti-RNP, Anti-U1RNP, Anti-Smith, Anti-SSA, Anti SSB, Anti Scl-70, Anti-Jo-1, Anti centromere Antibodies) was negative.

Biopsy and histopathology of the left breast lump revealed

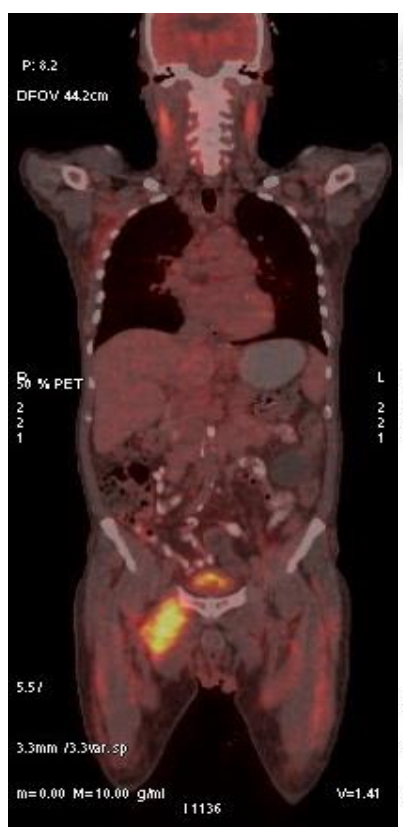

a circumscribed nodule of lymphoid cells, prominence of cells with vesicular chromatin \& conspicuous nucleoli, lymphoid cells observed to be infiltrating the surrounding skeletal muscle fibres. The cells were CD20 positive; CD3, CD5, CD10, CD23 negative; Ki-67 labelling index $80 \%$ on immunohistochemistry, suggesting a diagnosis of Non Hodgkin's Lymphoma, Diffuse Large B cell Type. A Positron Emission Tomography-Computed Tomography (PET-CT) Fig. (2). was done which revealed an increased Fludeoxyglucose (FDG) avidity in the right adductor compartment (Standardized uptake value SUV 10.3), right gluteal muscles (SUV 5.3), right parascapular muscles (SUV 7.2), left pectoralis major muscle (10.1), and left thigh muscles (7.9), suggestive of neoplastic etiology.

Patient required an initial period of stabilisation, dialysis, fluid and electrolyte management, glycemic control, control of sepsis and anticoagulation, apart from supportive treatment. The hypercalcemia and cortical vein thrombosis were considered to be paraneoplastic in etiology.

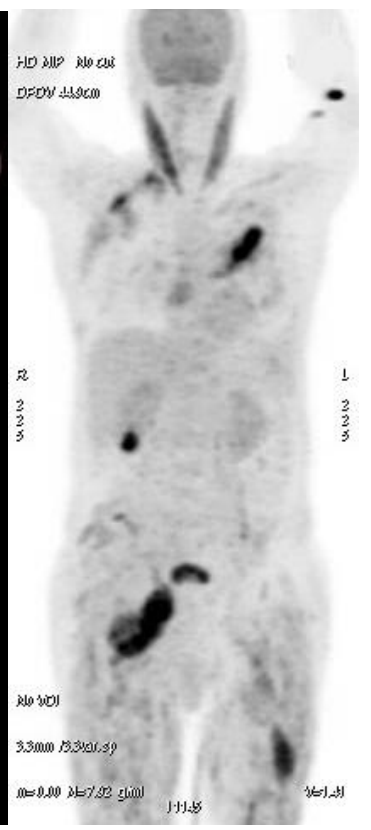

Fig. (2). PET-CT Images revealing high FDG Avidity in multiple skeletal muscles. 
Review of old records revealed an S.Creatinine of 0.7 $\mathrm{mg} / \mathrm{dl}$ and normal urine $\mathrm{r} / \mathrm{m}$ examination 1 year prior to this illness, indicating new onset proteinuria with renal dysfunction. The possibility of a glomerular pathology related to the neoplasia was considered, apart from diabetic nephropathy. Also, his renal dysfunction was possibly multifactorial, secondary to hypercalcemia, sepsis, and neoplasia. However, the patient refused to consent to the suggested renal biopsy.

Subsequently, chemotherapy initiation with R-CHOP (Rituximab, Cyclophosphamide, Doxorubicin, Vincristine and Prednisone) regimen revealed gradual clinical and biochemical improvement in his symptoms, observed through clinical and laboratory parameters. Following 8 weeks of treatment, he was found to be completely asymptomatic with S.Creatinine of 1.4 $\mathrm{mg} / \mathrm{dl}$, S.Ca $8.4 \mathrm{mg} / \mathrm{dl}$ and Spot Urine Protein/Creatinine Ratio 0.6 to 0.8 .

\section{DISCUSSION}

Primary skeletal muscle lymphoma although first reported by Kandel et al. in 1984 [8], is one of the rarest forms of Diffuse Large B Cell Lymphoma, with a reported incidence of $0.5-1.5 \%$ [9]. The presentation involves limb pain, swelling, and edema, commonly without significant overlying inflammation or at times a painless localised lump. Also rarely, there can be multiple sites of involvement, apart from the skeletal muscles $[6,10]$. Breast involvement is one of the uncommon sites of extranodal lymphoma, though it is more common than skeletal muscle involvement $[5,6]$.

Though imaging is the frequent initial step for the evaluation of such patients, the radiological features of skeletal muscle lymphoma are non-specific and cannot differentiate lymphoma from other conditions, such as myositis, trauma, sarcoma or metastasis. The diagnosis requires a skeletal muscle biopsy and histopathological examination. PET-CT has a significant role not only as a diagnostic modality, but also for staging and subsequently, for monitoring of therapeutic response [6].

Our patient had breast involvement as evidenced by the biopsy findings of the breast lump and multiple skeletal muscle involvement as evidenced by the PET-CT findings. A separate skeletal muscle biopsy was not considered since evidence provided by the breast biopsy and PET-CT was highly suggestive of the diagnosis.

Our patient also had hypercalcemia, cortical vein thrombosis, proteinuria and renal dysfunction of potentially neoplastic etiology. Hypercalcemia and Cortical vein thrombosis have been reported previously in association with NonHodgkin's lymphoma [11, 12].

Renal involvement secondary to direct lymphomatous infiltration; glomerulopathy as minimal change disease, membranous nephropathy, amyloidosis, monoclonal immunoglobulin deposition disease and immunotactoid glomerulopathy; and acute tubulointerstitial nephritis have all been reported with Non-Hodgkin's Lymphoma [13]. Possibly, our patient had glomerulopathy secondary to neoplasia, apart from underlying diabetic nephropathy. In addition, the renal dysfunction was multifactorial in etiology, with contributions from high calcium, initial sepsis, possibly a tubulointerstitial or direct renal lymphomatous involvement. In the absence of a renal biopsy in our patient, it remains speculative as to what factors and to what degree these factors contributed to the renal dysfunction and other presumed paraneoplastic manifestations.

The treatment protocol for skeletal muscle/extranodal lymphoma depends upon the specific subtype of NonHodgkin's lymphoma and the prognosis is worst as compared to nodal variety [6]. Our patient was found to have Diffuse Large B Cell sub type and was managed with chemotherapy (R-CHOP Regimen), to which he responded positively

\section{CONCLUSION}

Diffuse Large B Cell lymphoma, the commonest subtype of Non-Hodgkin's lymphoma, may present rarely with primary skeletal muscle and breast involvement. There may be multiple paraneoplastic manifestations in accompaniment. An early diagnosis is necessary for appropriate management to improve patient outcomes.

\section{ETHICS APPROVAL AND CONSENT TO PARTICIPATE}

Not applicable.

\section{HUMAN AND ANIMAL RIGHTS}

Not applicable.

\section{CONSENT FOR PUBLICATION}

Informed consent was obtained from the patient.

\section{STANDARD FOR REPORTING}

CARE guidelines and methodology were followed.

\section{CONFLICT OF INTEREST}

The authors declare no conflict of interest, financial or otherwise.

\section{ACKNOWLEDGEMENTS}

Declared none.

\section{REFERENCES}

[1] Prakash G, Sharma A, Raina V, Kumar L, Sharma MC, Mohanti BK. B cell non-Hodgkin's lymphoma: Experience from a tertiary care cancer center. Ann Hematol 2012; 91(10): 1603-11. [http://dx.doi.org/10.1007/s00277-012-1491-5] [PMID: 22584851]

[2] American Cancer Society. Cancer Facts \& Figures 2018.https://www.cancer.org/content/dam/cancer-org/research/cancerfacts-and-statistics/annual-cancer-facts-and-figures/2018/cancer-factsand-figures-2018.pdf

[3] McGuire S. World Cancer Report 2014. Geneva, Switzerland: World Health Organization, International Agency for Research on Cancer, WHO Press, 2015. Adv Nutr 2016; 7(2): 418-9.

[http://dx.doi.org/10.3945/an.116.012211] [PMID: 26980827]

[4] De Paepe P, De Wolf-Peeters C. Diffuse large B-cell lymphoma: A heterogeneous group of non-Hodgkin lymphomas comprising several distinct clinicopathological entities. Leukemia 2007; 21(1): 37-43. [http://dx.doi.org/10.1038/sj.leu.2404449] [PMID: 17039226]

[5] Møller MB, Pedersen NT, Christensen BE. Diffuse large B-cell lymphoma: Clinical implications of extranodal versus nodal presentation-a population-based study of 1575 cases. Br J Haematol 2004; 124(2): 151-9. 
[http://dx.doi.org/10.1046/j.1365-2141.2003.04749.x] [PMID: 14687 024]

[6] Zhang L, Lin Q, Zhang L, Dong L, Li Y. Primary skeletal muscle diffuse large B cell lymphoma: A case report and review of the literature. Oncol Lett 2015; 10(4): 2156-60.

[http://dx.doi.org/10.3892/ol.2015.3505] [PMID: 26622811]

[7] Chao Li, Lin Li. Multifocal extranodal lymphoma: A case report. Medicine 2016; 95(40): e5029.

[8] Kandel RA, Bédard YC, Pritzker KP, Luk SC. Lymphoma. Presenting as an intramuscular small cell malignant tumor. Cancer 1984; 53(7): 1586-9.

[http://dx.doi.org/10.1002/1097-0142(19840401)53:7<1586::AID-CN CR2820530727>3.0.CO;2-Z] [PMID: 6321011]

[9] Glass AG, Karnell LH, Menck HR. The National Cancer Data Base report on non-Hodgkin's lymphoma. Cancer 1997; 80(12): 2311-20. [http://dx.doi.org/10.1002/(SICI)1097-0142(19971215)80:12<2311::A ID-CNCR13>3.0.CO;2-X] [PMID: 9404709]

[10] Damron TA, Le MH. Lymphoma presenting as a soft tissue mass. A soft tissue sarcoma simulator. Orthop Relat Res 1999; (360): 221-30.

[11] Majumdar G. Incidence and prognostic significance of hypercalcaemia in B-cell non-Hodgkin's lymphoma. J Clin Pathol 2002; 55(8): 637-8. [http://dx.doi.org/10.1136/jcp.55.8.637-a] [PMID: 12147666]

[12] Kumar P, Ahmed R. Cerebral venous thrombosis in adolescents and young adults with classical hodgkin lymphoma. Blood 2012; 120 : 4784

[13] Cohen LJ, Rennke HG, Laubach JP, Humphreys BD. The spectrum of kidney involvement in lymphoma: A case report and review of the literature. Am J Kidney Dis 2010; 56(6): 1191-6. [http://dx.doi.org/10.1053/j.ajkd.2010.07.009] [PMID: 20843590]

\section{C) 2019 Dassi. et al.}

This is an open access article distributed under the terms of the Creative Commons Attribution 4.0 International Public License (CC-BY 4.0), a copy of which is available at: https://creativecommons.org/licenses/by/4.0/legalcode. This license permits unrestricted use, distribution, and reproduction in any medium, provided the original author and source are credited. 